\title{
A memória e os objetos: interpretações sobre o filme brasileiro "O palhaço"
}

\author{
Thememory and the objects: interpretations of the Brazilian \\ movie "The clown"
}

\author{
Enviado em: 10/05/2018 \\ Aceito em: 20/07/2018 \\ Darlan De Mamann Marchi ${ }^{1}$ \\ Olivia Silva Nery²
}

\begin{abstract}
Resumo:
O filme "O Palhaço" (2011), do ator e diretor brasileiro Selton Mello, permite discutir algumas questões em torno da memória e da identidade. O palhaço circense Benjamin, protagonista do filme, e interpretado por Mello, sofre uma crise de identidade. Vivendo no espaço de um ofício tradicional sob a lona do circo, o personagem é afetado pela realidade de um mundo repleto de transformações. No documentário sobre a produção do filme, Mello fala da importância que teve um chapéu, utilizado pelo seu personagem Benjamin, para a concepção da obra. No roteiro da obra, quando vive seus dilemas, o palhaço materializa-os na metáfora de outro objeto: um ventilador. Estes objetos que compõem o universo do filme são os elementos que se utiliza, para a análise do mesmo nesse artigo.
\end{abstract}

Palavras-chave: palhaço; circo; memória; objetos; identidade.

\begin{abstract}
:
The movie "The Clown" (2011) was conceived for brazilian actor and director Selton Mello and discuss some issues about memory and identity. The clown Benjamin, is the protagonist of the movie, interpreted by Mello, he has a crisis of identity. Living in a space of a traditional work under the circus tent, the character is affected by the reality of a
\end{abstract}

\footnotetext{
${ }^{1}$ Doutor em Memória Social e Patrimônio Cultural da Universidade Federal de Pelotas (2018); Mestre em Memória Social e Patrimônio Cultural pela Universidade Federal de Pelotas (2014). Licenciado em História pela Universidade Regional Integrada do Alto Uruguai e das Missões - URI Campus Santo Ângelo (2007).

2 Doutoranda (Bolsista CAPES) em História pela Pontifícia Universidade Católica do Rio Grande do Sul PUCRS; Mestre em Memória Social e Patrimônio Cultural pela Universidade Federal de Pelotas - UFPel, e Bacharela em História pela Universidade Federal do Rio Grande - FURG.
} 
modern world full of changes. In the documentary about the making of the movie Mello speaks of the importance of a hat, used by your character Benjamin, for the design of film work. In the movie script, when he's living his dilemmas, the clown materializes them through a metaphor of another object: a fan. The objects make up the universe of the movie and are the elements that are used for the analysis movie work in this article.

Keywords: clown; circus; memory; objects; identity.

\section{Considerações Iniciais:}

A obra fílmica "O Palhaço" de 2011, dirigida e protagonizada pelo ator e diretor brasileiro Selton Mello, tem como pano de fundo o cotidiano de um grupo de artistas circenses e a vida errante junto ao Circo Esperança. O circo é de propriedade de Valdemar (Paulo José) e do filho Benjamin (Selton Mello), que formam a dupla de palhaços Pangaré e Puro Sangue. Benjamim se vê sobrecarregado pelas responsabilidades de futuro gerenciador do circo. O ofício de fazer rir está atravessado pelos dilemas pessoais de Benjamin, um palhaço jovem, que faz a alegria do público, mas que está dividido entre a tradição, com a continuidade do trabalho do pai, e as possibilidades de outra vida fora da lona. Da atividade do circo depende a sobrevivência de toda a trupe formada por dançarina, contorcionista, malabaristas, mágico, músicos e outros artistas que se juntam ao show de variedades que ocorre sob a lona.

A história se passa num espaço temporal não identificado, mas que, através dos figurinos e outros elementos de cena, remete possivelmente as últimas décadas do século passado. O ambiente ruralizado das cidades interioranas e $\mathrm{o}$ ar bucólico, que se mescla com sintomas de uma sociedade tecnológica em transformação, dá o tom para a trama que se desenrola. Todo o clima criado pela fotografia da obra, entre a mágica do picadeiro e a dureza da realidade fora da cena, reflete de alguma maneira, os conflitos vividos pelo personagem de Selton Mello, um palhaço de formação familiar no limiar entre a continuidade da tradição circense e a vida sedentária das cidades modernas. A fantasia do picadeiro contrasta com as responsabilidades de levar adiante essa atividade secular sob a qual Benjamin principia a questionar-se. As relações que se estabelecem nos lugares por onde passam e a fugacidade dessas relações são também os pontos de questionamento de Benjamin sobre sua própria identidade. Seguir o trabalho do circo ou fixar-se em um emprego estável e abandonar a tradição? Render-se aos novos tempos e às possibilidades de uma vida com um emprego relativamente seguro em um centro 
moderno ou seguir sem rumo pelas estradas do país? Estas são algumas das questões que passam a fazer parte dos daquele momento da vida do jovem palhaço.

A crise de identidade vivida pelo protagonista do filme pode ser discutida a partir da representação feita através de objetos que aparecem no filme. O ventilador, objeto de desejo de Benjamin no decorrer da história, metaforiza as questões pessoais pelas quais atravessa o jovem palhaço. No mesmo norte da discussão também se trabalha a partir do chapéu do personagem, destacado pelo ator Selton Mello, no documentário sobre os bastidores da filmagem, como objeto que o acompanhou durante todo o processo de criação. Tanto o chapéu para o ator como o ventilador para o palhaço, podem ser compreendidos enquanto dispositivos para a realização da obra fílmica. Assim, o poder simbólico dos objetos perpassa pela realidade, ou seja, os bastidores da produção da obra, assim como adentra o espaço da ficção enquanto elemento que materializa os conflitos internos do personagem.

Dessa forma, o artigo busca refletir sobre as possibilidades de interpretação que o filme apresenta com relação a tradição circense, a identidade, a memória e os objetos como representantes materiais desse universo. Assim, o longa-metragem de Selton Mello passa a ser uma fonte de estudo e de aproximação entre dois mundos que se interconectam nas suas subjetividades. Quanto da realidade se transpõe à ficção e viceversa? O que a ficção nos mostra sobre a realidade?

Inicia-se discutindo o circo e o palhaço como espaço e figura que congregam aspectos memoriais de uma atividade profissional tradicional. Posteriormente discute-se dialeticamente, à luz de alguns pensadores do campo da memória e da cultura material, as relações da própria dialética sob a qual se construiu a obra fílmica. A construção dos personagens, o desenrolar da trama e os objetos que compõem a metáfora da obra, servem como pontos de análise para discutir o entrecruzamento desses mundos e a interposição entre a realidade e a ficção, entre tradição e modernidade.

\section{O palhaço e o circo: tradição e memória}

O palhaço de nariz vermelho, com grandes sapatos, roupa colorida e boca pintada não pode ser visto fora de uma compreensão memorial que constituiu esses gêneros e tipos cômicos que foram se definindo ao longo dos séculos. Há uma construção temporal dessas figuras, uma compilação de técnicas provenientes dos rituais e de outros modos de expressão até então dissolvidas na estrutura social de diferentes grupos humanos. A 
teatralidade popular é a base do palhaço; ele engloba esse aspecto mundano e, por isso, é repleto de representações da materialidade humana e dos seus engodos, defeitos e fragilidades.

Peter Burke (1989, p.52) aborda o palhaço como exemplo de um personagem que esteve presente "tanto nas cortes como nas tavernas". Os cômicos, os bufões, os bobos, os clowns e, posteriormente, os palhaços, como se conhece hoje, há muito tempo encontravam-se inseridos no tecido social de diferentes comunidades. Para Bakhtin (2010, p.07), a figura do cômico e a dos bufões provocadores do riso eram, no cotidiano, uma extensão do período carnavalesco, constituindo-se como figuras que se estabeleciam entre a vida real e a vida ideal. Esses personagens representavam essa ligação do homem com ele mesmo, com sua humanidade corporal e mundana.

As formas do cômico popular da praça pública constituíam também uma das fontes importantes da imagem grotesca do corpo. [...]. Todos esses acrobatas, funâmbulos e triagueiros, etc., eram atletas, prestidigitadores, bufões, apresentadores de macacos (réplicas grotescas do homem), vendedores de panacéias universais. $O$ universo das formas cômicas que eles cultivavam era o universo do corpo grotesco nitidamente expresso. Hoje ainda, é nos espetáculos de feira, e num grau menor no circo, que o corpo grotesco se conserva melhor (BAKHTIN, 2010, p.309).

O cômico grotesco abordado por Bakhtin é um elemento que se transforma ao longo das modificações que as estruturas sociais sofrem com o passar do tempo. A atuação do risível nas sociedades é modificada conforme se reestruturam as mentalidades de cada época. Por isso,no período medieval policiava-se o riso deliberado, antes presente com toda sua força nas sociedades primitivas, passando a regulá-lo nos espaços oficiais. Porém, essa tentativa de conter a zombaria, impedindo que as relações de poder instituídas não fossem expostas ao escárnio, não teve eficácia junto aos espaços populares. Nesses locais, onde circulava a plebe e os que estavam distantes dos espaços políticos e religiosos oficiais, o riso seguia fazendo parte do cotidiano. Dentro desses diferentes tempos, movidos por questões sociais e culturais bastante particulares, é que o cômico foi definindo novos gêneros e firmando alguns personagens que se tornaram marcantes nas formas artísticas da comédia, como é o caso do palhaço.

O palhaço, restrito ao espaço da lona conforme o senso comum contemporâneo, é muito anterior ao circo tal qual se conhece hoje. O circo moderno surgiu em Londres na segunda metade do século XVIII sob a direção de Philip Astley, membro da cavalaria inglesa que construiu um espaço específico para a demonstração de números de cavalaria antes realizados em locais públicos. Desse empreendimento, assim como de 
outros que surgiram no período, é que advém a expressão que remete ao "circo de cavalinhos". Astley expandiu seus negócios e levou a atividade também para Paris, mesmo período no qual inseriu elementos cômicos ligados ao cavalo e que foram aprimorados em seu encontro com Antonio Franconi, o qual tinha atividades artísticas ligadas aos espetáculos populares e acabou adicionando ao Anfiteatro de Astley a pantomima e outras atrações, passando a constituir o espetáculo circense conhecido na atualidade (BOLOGNESI, 2003, p. 31-32). Nesse período, o circo era um espetáculo de lazer e entretenimento nem tão popular, pois era voltado para um público aristocrata que

\begin{abstract}
[...] encontrou com o circo, um modo de tornar espetacular o seu mais caro símbolo social, o cavalo. Em meio à onda revolucionária, sob a forma de um espetáculo detalhadamente organizado e administrado por um empresário (distante, portanto, da espontaneidade predominante dos espetáculos das feiras), o circo concentrava os ideais de uma classe que estava prestes a perder seu lugar na dominação social(BOLOGNESI apud AUGEST, ibidem).
\end{abstract}

Dentro desse esquema de espetáculo, no qual há o encontro do espetáculo militarizado das demonstrações das habilidades equestres com as tradicionais comicidades dos artistas das ruas, é que surge o circo como um aglutinador dessas representações culturais que ora uniam, ora separavam os homens conforme suas organizações sociais e hierárquicas. O circo fixa-se como uma tradição surgida desse ambiente ambivalente, e é essa ambivalência que vai marcar também algumas relações da atuação dos cômicos no espaço do circo. Um exemplo claro dessas relações está na figura do clown e no seu desdobramento entre o clown branco e o clown augusto. Essa relação é definida por Fo:

\footnotetext{
Nos espetáculos de clown existe sempre um clown de grande loquacidade, que investe como uma metralhadora de palavras contra o público e os outros clowns. Porém, há outro, quase sempre mudo, que escuta, assente apenas, discorda com muito garbo, lança olhares perdidos, fica estupefato por qualquer coisa, até a mais banal. O primeiro é o speaker, o clown branco, o Louis; o segundo é o Auguste. Contrariando as aparências, o personagem principal é o que não fala; o Louis é que é o apoio (FO, 2004, p.208).
}

Fruto do encontro entre a bufonaria das ruas e a pantomima inglesa, a dupla de clowns é herdeira das relações estabelecidas na commedia dell'arte entre personagens como o Arlequim e a Colombina. Eles definirão, não só no espaço circense, essa atrapalhada e cômica interação que vai influenciar a comédia moderna e marcar o cinema como, por exemplo, Chaplin e seu personagem Carlitos, uma espécie de clown branco, ou as situações desencadeadas pela famosa dupla de atores Oliver Hardy e Stan 
Laurel e seus personagens, o Gordo e o Magro. Ainda no cinema brasileiro do século passado encontram-se exemplos, como os inúmeros filmes da dupla Oscarito e Grande Otelo. Todos esses personagens dialogam com o público, a cultura e o tempo em que estão colocados e assumem identidades próprias, mas o jogo e as relações que provocam o riso possuem um fio que os liga a uma memória do risível produzida pelo acúmulo das influências cômicas de diferentes épocas.

Outro aspecto definidor do estilo circense que aparece no filme "O palhaço" é a itinerância da atividade pelo interior do país. A modalidade de apresentação teatral itinerante se inicia no Brasil, conforme Silva (2007), com a introdução do teatro popular no circo nacional, a partir do final do século XIX, através do cômico Benjamin de Oliveira, um dos precursores do circo-teatro brasileiro. Selton Mello faz uma homenagem ao precursor do circo-teatro brasileiro ao batizar seu personagem no filme com o mesmo nome ${ }^{3}$. Em o "Circo-teatro: Benjamim de Oliveira e a teatralidade circense no Brasil", a historiadora do circo Ermínia Silva (2007) relata que,além de palhaço, Benjamin era cantor e compositor e afirma ter sido o primeiro a inserir o teatro no espaço circense. Sousa Junior (apud RUIZ, 2008, p. 35) cita entrevista dada por Benjamin de Oliveira a Revista Dom Casmurro, na qual ele afirma que, junto ao circo Spinelli, foi o responsável pelo lançamento "dessa forma de teatro combinado com circo que mais tarde tomaria o nome de Pavilhão".

Inspirado na vida destes artistas, o longa-metragem de Selton Mello consegue retratar, através do pequeno circo familiar contemporâneo, como essa tradição do ofício de fazer rir chegou até os dias atuais. Num pequeno circo alternativo que mistura linguagens artísticas, a dupla de clowns formada por pai e filho, os palhaços Pangaré e Puro Sangue, clowns branco e augusto, desvelam o fio memorial dessa arte que transcende os séculos e que reflete em um saber-fazer desses artistas autodidatas. Sobre a análise dessa atividade nos circos brasileiros Bolognesi afirma que:

No Brasil, no meio circense, é comum ouvir-se o termo crom em referência àquele palhaço que tem a função de partner, ou de palhaço secundário. É ele quem opera como contraponto preparatório às piadas ou gags do palhaço principal. Ele também é chamado de escada (Bolognesi, 2003, p.62).

$\mathrm{Na}$ figura do clown Augusto está o princípio do palhaço de nariz avermelhado, trapalhão, desajeitado, estúpido e grosseiro, que se envolve em inúmeras confusões, e

3 O Palhaço. Disponível em: <http://www.cca.eca.usp.br/educomcinema palhaco > Acesso em 27 de abril de 2015. 
que no filme é papel interpretado por Benjamin quando está no picadeiro ao lado do pai (figura 1). No Brasil, o termo palhaço popularizou esse ser híbrido, que adquiriu inúmeros outros formatos, mesmo assim manteve características que o assemelham ao clown (BOLOGNESI, 2003, p.74). O palhaço como sendo aquele que veste a roupa ao contrário, que perde as calças em cena, que fala impropérios, que joga com o corpo e que utiliza toda a sua malícia em uma performance cômica ao molde rabelaisiano. Portanto, o corpo é algo extremamente essencial: ele expõe os limites da materialidade humana e, por consequência, os limites do mundo ao homem, que só vive o mundo através dessa materialidade.

Figura 1 - Paulo José e Selton Mello. Palhaços Pangaré e Puro Sangue.

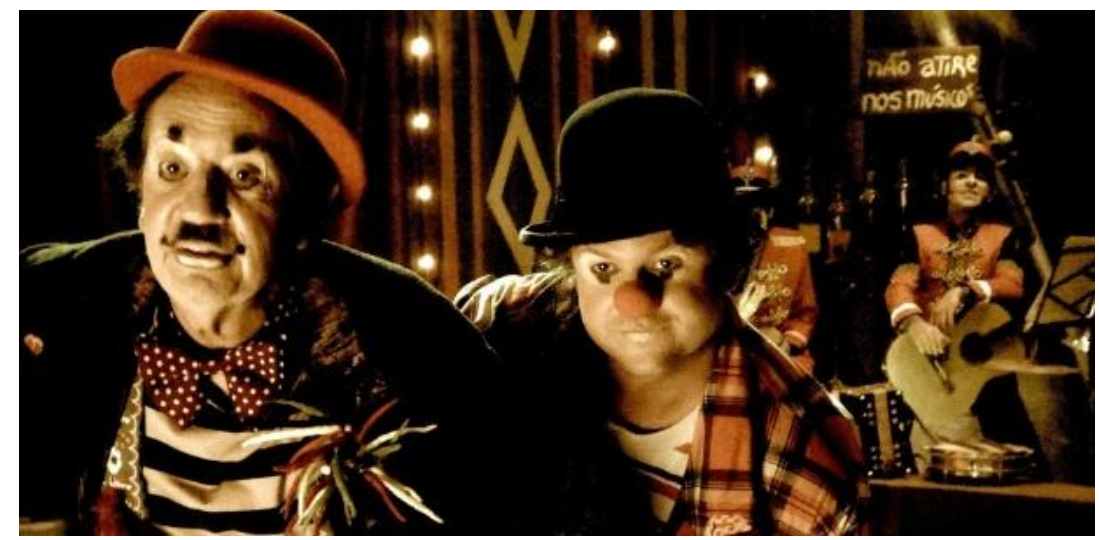

Cena do filme "O Palhaço". Fonte:

$<$ http://cinema.uol.com.br/noticias/redacao/2012/11/20/o-palhaco-e-eleito-melhor-filmeno-3-festival-brapeq-de-cinema-brasileiro-na-china.htm> Acesso em 27 de abril de 2015.

O nariz do palhaço talvez tenha ficado avermelhado ao cair com a cara no chão, provocando risos na plateia ${ }^{4}$. No entanto, o nariz é um fator preponderante para o risível, trata-se de uma representação do falo, ganhando proporções enormes que o tornam grotesco, e que se expressa em diferentes máscaras de distintos personagens cômicos. Depois do nariz, a boca escancarada e devoradora assim como o ventre e o traseiro protuberantes são bases do corpo grotesco. Unidos e em destaque, além de artifícios amplamente utilizados pelo palhaço em cena, representam lugares do corpo onde estão os orifícios. Lugares de absorção e excreção, "onde se ultrapassam as fronteiras entre

\footnotetext{
${ }^{4}$ Bolognesi (2003: 74) relembra a história do cavaleiro e acrobata Tom Belling, que, embriagado, cai do cavalo em uma de suas apresentações no picadeiro. Percebendo que as trapalhadas renderam risadas, acabou aprimorando esse personagem com o uso de uma peruca, um paletó ao avesso e o nariz pintado. $\mathrm{O}$ sucesso desse personagem torna-se uma emblemática explicação para o aparecimento do clown Augusto.
} 
dois corpos e entre o corpo e o mundo", lugares de troca, do princípio e do fim da vida (BAKHTIN, 2010, p.276-277).

Os tipos grotescos, o anão, o homem extremamente alto e magro, a mulher de seios avantajados, compõem o elenco do circo retratado no filme de Mello. A corporeidade dos tipos cômicos e suas ações no picadeiro têm a função de provocar o riso através das ações torpes e apelativas, escarnecendo dos valores morais impostos no âmbito das relações sociais estabelecidas entre os artistas e os poderes oficiais instituídos nos lugares por onde passam. Cabe a ao palhaço, em uma espécie de pacto consentido pelo lugar que ocupa, através do personagem que assume, amainar através do cômico essa seriedade impregnada nos vínculos sociais. A ele é dado esse consentimento, porém, isso nem sempre ocorre de maneira tranquila.

Numa das cenas de "O Palhaço", o prefeito de uma das cidadezinhas visitadas pela trupe está na plateia e o palhaço brinca com ele e com sua esposa. $\mathrm{O}$ casal mais influente da cidade gentilmente convida a todos do circo para jantar em sua casa. Entretanto, durante o jantar, o interesse se sobrepõe à gentileza, pois, na verdade, o prefeito desejava que os artistas inserissem o seu filho, que não demonstrava nenhuma aptidão artística, num dos números no picadeiro. Esta situação, comicamente explorada no filme,demonstra que as relações de poder estabelecidas também fazem parte do trabalho dos artistas que vivem no limiar entre a função de zombar desses poderes e a dependência destes poderes para seguir com seu trabalho.

Quando Michel de Certeau (1990) fala da arte popular, exemplificando a realidade do povo sertanejo do nordeste brasileiro, e a forma como as pessoas precisam se utilizar dessas regras impostas pela força do Estado opressor para criar, em cima disso, suas utopias, uma espécie de "não-lugar", que os permita resistir, ele faz a seguinte comparação:

\begin{abstract}
Uma prática da ordem construída por outros redistribui-lhe o espaço. Ali ela cria ao menos um jogo, por manobras entre forças desiguais e por referências utópicas. Aí se manifestaria a opacidade da cultura "popular" - a pedra negra que se opõe à assimilação. O que aí se chama sabedoria, define-se como trampolinagem, palavra que um jogo de palavras associa à acrobacia do saltimbanco e à sua arte de saltar no trampolim, e como trapaçaria, astúcia e esperteza no modo de utilizar ou driblar os termos dos contratos sociais. Mil maneiras de jogar/desfazer o jogo do outro, ou seja, o espaço instituído por outros, caracterizam a atividade sutil, tenaz, resistente, de grupos que por não ter um próprio, devem desembaraçar-se em uma rede de forças e representações estabelecidas. Nesses estratagemas de combatentes existe uma arte dos golpes, dos lances, um prazer em alterar as regras de espaço opressor. Destreza tática e alegria de uma tecnicidade. Scapin e Fígaro são apenas ecos literários desse modo de agir (CERTEAU, 1990: 79).
\end{abstract}


Os artistas itinerantes utilizam-se da "trampolinagem" não apenas no palco, no jogo do palhaço espertalhão que precisa sobreviver, e, por isso, usam de todas as artimanhas para obter sucesso em seus intentos. Os artistas do circo precisam executar isso na vida real também, essa é condição para seguirem fazendo aquilo que sabem. $A$ resistência é um traço da memória da cultura popular, assim como transformar em risível essas dificuldades. Sempre estiveram ligados a um grupo acostumado com a luta pela sobrevivência, e é para esse grupo que passam a mostrar seu trabalho e é de si e dessa relação com os demais que reelaboram sua arte em uma linguagem que os identifica.

Esses princípios definidores do saber-fazer dos palhaços circenses são alegorias utilizadas por Selton Mello para o enredo da obra fílmica. O palhaço que faz rir também faz chorar quando se confronta com sua humanidade e os dilemas que traz consigo. $O$ palhaço é assim um ser ancestral, mas também um homem de seu tempo, atravessado pelas dúvidas e pelos jogos de poder de uma sociedade em constante transformação.

No documentário "Palhaço.doc" dirigido por Marcelo Pontes, no qual os artistas e a equipe que participaram do longa-metragem falam do processo de trabalho, Selton Mello lê um texto que expressa o clima que circula pelo decorrer de toda a obra fílmica. $\mathrm{O}$ texto diz o seguinte:

\begin{abstract}
Os palhaços raramente eram apenas palhaços. O palhaço tinha outras técnicas, podia ser a música, a acrobacia, o malabarismo, ser amestrador de animais. Meu pai sempre dizia que não se começava sendo palhaço, isso vinha depois. A primeira coisa era aprender um ofício, uma técnica. E com a vida, com a experiência do contato humano e com o gosto de ter contato humano lentamente a técnica ia se tornando menos importante e o mais importante ficaria sendo a personalidade. [...] O fato de se morar dentro da cerca, com pouco contato com o mundo lá fora, faz com que a convivência familiar seja mais intensa. O palhaço permanece sempre no absurdo. Sempre no imaginário, no paradoxo, no grotesco. O palhaço deve fazer rir e pensar, sonhar e refletir. O palhaço não tem psicologismos, sua lógica é física. Ele pensa e sente com o corpo. [...] na medida em que o mundo perde cada dia mais a capacidade de brincar e se reinventar, ainda mais fundamental se torna a figura do palhaço, esse viajante do tempo e na história da humanidade (2011,4:06 - 5:45).
\end{abstract}

Encontram-se, nesse breve trecho, aspectos que denotam pontos cruciais do ofício do palhaço: a aprendizagem cotidiana, a vivência familiar, a preponderância do corpo e do grotesco e atividade memorialística que marca esse compartilhamento da técnica. O caráter itinerante do circo, também outro aspecto que faz parte da realidade desse "viajante do tempo", como diz o texto, é elemento importante da transmissão da memória. Esse lugar em movimento evidencia o lugar no mundo desse artista que aprendeu, nesse ambiente de trocas que é o circo, o ofício de fazer rir. Não há um 
espaço geográfico, um bairro, uma rua, uma cidade, mas sim uma atividade sem território fixo, que se constitui memorialmente nesse ambiente instável para os padrões modernos de uma sociedade ocidental.

Nesse ponto, a transmissão dos conhecimentos tem um papel preponderante, afinal, essa identidade se afirma no ato de absorver os saberes constituídos nesse e para esse lugar, apesar de todas as adversidades trazidas pelas mudanças e desafios de cada tempo e espaço. O palco, o ônibus e a lona passam a ser a paisagem de referência, e a família e o teatro passaram a ser os principais pontos do sentimento de pertencimento.

A atividade circense é um saber fazer compartilhado através da transmissão familiar. Segundo Ermínia Silva (2008, p.19) “o circense, até as décadas de 1950/60, na sua maioria, nascia sob a lona ou a ela se juntava. A formação e a aprendizagem tinham início desde o seu nascimento [...]. Dessa forma, volta-se para Maurice Halbwachs (1990, p.39) que afirma que é no âmbito familiar que a memória está em seu estado mais fortalecido, sendo que na infância a pessoa adquire as memórias que a situam em um espaço de pertencimento. Mesmo com as rupturas que possa ter sofrido no decorrer da vida, através da sua inserção em outros grupos e de novas e sucessivas experiências, sua base inicial de pertencimento continua sendo a família, pois, "[...]é no quadro da família que a imagem se situa, porque desde o início ela estava ali inserida e dela jamais saiu".

Todos esses aspectos memoriais, discutidos até aqui, compõem o cotidiano do palhaço e estão ora mais explícitos, ora mais subentendidos no decorrer do filme "O Palhaço". Todos esses elementos são constituidores da formação do palhaço e se somam aos dilemas pelo qual passa o personagem de Mello, o jovem Benjamin.

\section{Além do material: o ventilador, o chapéu e os simbolismos}

O processo de dar continuidade a um ofício, muito além de apenas ser um desejo de um grupo ou um apego aos traços familiares repassados, é também gerado na necessidade de sobreviver a partir daquilo que se sabe, no caso do palhaço, através da encenação e das situações cênicas risíveis aprendidas, repassadas e repetidas no decorrer da convivência afetiva balizada pelas relações parentais. No filme, o personagem Benjamin atravessa uma crise pessoal, devido a força dos novos tempos com seu modelo sedentário, instável e tecnológico de sociedade, o que faz com que o jovem palhaço passe a viver nessa ambiguidade entre o passado da tradição e o presente das incertezas frente ao desejo de buscar novos caminhos e de poder fazer 
outras escolhas. O universo da obra e as angústias vividas pelo protagonista têm como mola propulsora aquilo que Hall (2011, p.84) chama de viver "num mundo de fronteiras dissolvidas e de continuidades rompidas", onde ocorre o confronto de diferenças culturais e a ruptura das certezas e categorias tranquilizadoras da tradição.

Selton Mello opta no filme por expressar isso, entre outras formas, através da metáfora dos objetos. As dúvidas de Benjamin e seus desencontros identitários estão marcados de alguma maneira pela presença do objeto. O simbolismo se expressa na materialidade, no desejo de posse de um bem, na busca pelo novo, pelo "moderno", na tentativa de mudar de vida e adaptar-se aos novos tempos.

Dentro do longa-metragem existem personagens, falas e objetos que acabam chamando a atenção e, muitas vezes, "roubando a cena". Um destes, podemos dizer, é o ventilador. Ele aparece desde a primeira cena do filme, quando a colega de circo, Lola, fala para Benjamin sobre a necessidade de ele possuir um ventilador no seu camarim. A partir desse momento, o ventilador aparece durante toda a história com um aspecto simbólico extremamente forte e marcante, e, por vezes, ele é visto de acordo com a sua função original: de ventilar; por outras, nos confundimos com a utilização quase metafórica do objeto.

O personagem de Selton Mello sofre uma crise de identidade, sendo esse 0 enredo principal do filme. Essa crise é mediada pela presença do ventilador que aparece em momentos específicos e, ao mesmo tempo, importantes. Dentre as diversas interpretações possíveis que podemos associar ao ventilador e a sua escolha pelo criador da obra, uma delas é apresentada pela crítica do site Cine Pipoca Cult, que relaciona a presença do ventilador com os novos ares e mudanças que Benjamin procura, por outro lado, "[...] é a partir do ventilador que surge outros símbolos: RG, CPF e comprovante de residência. Uma falsa estabilidade, um falso conforto, um falso sorriso" (AUAD, 2011) 5 .

Além desta interpretação, também podemos associar o ventilador não só com os novos ares e rumos que o personagem busca, mas também à sua própria identidade. Numa das cenas, diversos tipos de ventiladores aparecem e Benjamim apenas os observa. Inicialmente, aparecem desligados, todavia, é a imaginação de Benjamim ao observar o ventilador que faz ele se movimentar. Como se ele funcionasse apenas na imaginação do personagem, e no cotidiano estivesse desligado ou estragado. O movimento do ventilador pode estar associado aos novos ares - além das fronteiras do

\footnotetext{
${ }^{5}$ Cine Pipoca Cult - O Palhaço: http://www.cinepipocacult.com.br/2011/10/o-palhaco.html
} 
circo - que permeiam o enredo do filme. As experiências externas à lona do circo começam a se mostrar interessantes, são experiências que Benjamim e seus colegas vivenciam em conjunto ou individualmente e que fazem os personagens refletirem sobre a condição de circense, as dificuldades e sobre o papel do próprio circo. A busca por novas experiências está associada à busca por seu lugar naquele mundo, naquele contexto do circo. Pesando a possibilidade de abandonar a vida de artista itinerante para encontrar-se.

De uma forma metafórica, a busca pela identidade de Benjamim está relacionada com a busca pelo ventilador, as duas se cruzam frente à crise vivida pelo personagem. Benjamin e seu grupo de amigos passam por várias situações adversas, como no caso em que vão parar na delegacia devido ao envolvimento em uma briga no bar da cidade. Naquele instante, diante do delegado, Benjamim sente-se perdido, deslocado, pensando na situação em que se encontram e, mais uma vez, a sua identidade é posta em questão. Nessa cena o ventilador reaparece, chamando a atenção do palhaço, que ao fitá-lo, movimenta as hélices.

Essa relação pode ser percebida em todas as fases em que o personagem aparece com a sua profissão e sua condição de palhaço. Conforme dito anteriormente, na primeira cena, quando aparece desmotivado em seu camarim, em um tom quase depressivo, surge a necessidade de um ventilador. Inicialmente ele está associado ao calor, diretamente relacionado à sua função patente de ventilar. No decorrer da história, percebemos que ele está ligado, além disso, a própria busca do "eu" de Benjamin, de uma mudança de vida, de status, de novos ares. Essa associação pode ser relacionada com a condição de status que atribuímos aos objetos que nós possuímos ou desejamos possuir. Nessa perspectiva, Marcus Dohmann nos apresenta a seguinte reflexão:

\footnotetext{
[...] todos os dias, um mundo de imagens invade nossos lares, mostrando objetos que temos; que gostaríamos de possuir ou cremos que devamos ter, criando novas expectativas que nos farão mais felizes, saudáveis ou atraentes. $\mathrm{O}$ utilitarismo explícito do objeto cede lugar ao reflexo a própria imagem do seu legítimo possuidor, que assim é constantemente motivado ao destacar sua existência individual no comportamento coletivo (DOHMANN, 2013, p.33).
}

Nesse sentido, a materialidade das coisas está diretamente vinculada ao seu aspecto utilitário, mas também de distinção social, de signo, de status e demais significados que atribuímos a eles. São materiais simbólicos que recebem a nossa influência memorial, mas que ao mesmo tempo influenciam na nossa maneira de ser e estar. Nesse momento, o ventilador deixa de ser apenas um ventilador e ganha um valor 
simbólico e reflexivo para o personagem, sua busca incessante ultrapassa a necessidade material de amenizar o calor, e passa a materializar a subjetividade da busca por encontrar-se.

O ventilador, apesar de ser um objeto relativamente popular, torna-se difícil de ser adquirido por Benjamin frente às dificuldades financeiras que ele passa. Mas o personagem não desiste, tentando comprá-lo diversas vezes. Em outros momentos, o objeto aparece compondo os cenários domésticos, profissionais e comerciais, chamando a atenção de Benjamim, mas podendo passar despercebido pelos olhares do espectador.

Angustiado pela profissão que parece não o satisfazer mais, Benjamim deixa o circo de seu pai e seus amigos para tentar outra vida, fora do picadeiro e da lona, indo conhecer a moça que havia, no final do espetáculo, elogiado seu trabalho. Desinteressado pela vida que tem levado e passando por problemas financeiros, o palhaço abandona o circo e sai na busca pela menina de Passos (nome da cidade na qual ela mora). Longe do circo o personagem acaba trabalhando no comércio e ironicamente rodeado por inúmeros ventiladores.

$\mathrm{Na}$ figura 2 podemos ver a cena a qual Benjamin está cercado por ventiladores. Apesar do personagem estar no centro, os ventiladores que o cercam chamam atenção do olhar. De diversas cores e tamanhos, Benjamin aparece quase perdido em meio às hélices. O semblante do personagem demonstra um desconforto com a situação, retratando o conflito em que vive: distante do picadeiro e do cotidiano interiorano e itinerante, e colocado agora no centro de uma realidade urbana, com referenciais sedentários e modernizantes.

Figura 2 - Benjamim e os ventiladores.

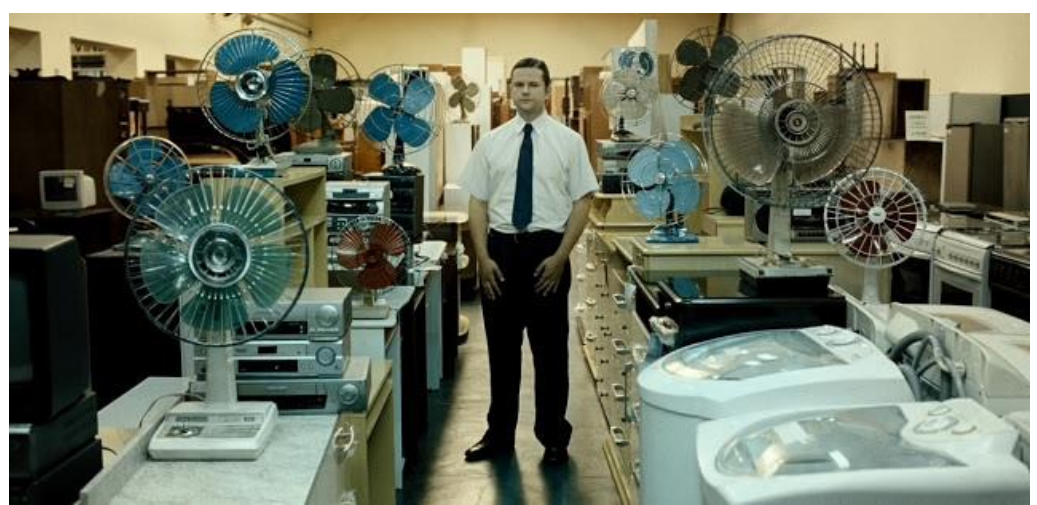

Fonte: http://euodeiocinefilos.blogspot.com.br/2013/02/o-palhaco.html. Acessado em 07 de setembro de 2015. 
Mesmo se esforçando para trabalhar fora do circo e encontrar a garota, Benjamin sofre a decepção de encontrá-la casada. A partir da desilusão amorosa, Benjamim começa a prestar atenção nos detalhes à sua volta, e na falta que os risos e gargalhadas do público fazem em sua vida, especialmente na cena em que ele aparece em um jantar com os seus colegas da empresa em que agora trabalha e onde todos riem. O ventilador volta a aparecer, e ao observar a risada das pessoas e o efeito delas nos sujeitos, ele parece achar o que estava perdido, percebendo que havia se encontrado.

$\mathrm{Na}$ carona de uma bicicleta, Benjamim aparece com o ventilador na mão, recém comprado, sorrindo, feliz e realizado. Ao voltar para casa, Benjamin não leva apenas o ventilador, mas algo além da sua materialidade, sua identidade restabelecida e a certeza de ter encontrado o seu lugar no mundo: o circo. Na volta para casa, na caçamba de um caminhão, onde faz graça para uma jovem moça boia-fria que segue no mesmo veículo, o ventilador está girando, mas agora não com a imaginação de Benjamim, mas com o passar do vento pelas suas hélices. Os novos ares chegaram e o levaram para debaixo da lona novamente, e o sorriso da moça confirma o motivo de sua volta: encontrou seu lugar e voltou para casa, carregando essa identidade viva e renovada.

Guilhermina, interpretada por Larissa Manoela, é a criança amiga do Benjamin que se mostra desde o início atenta e preocupada com as inquietações do amigo. Filha de dois circenses, ao final do filme ela estreia no papel de Lola que deixou o grupo; realizada pelo novo papel e pelo êxito da encenação, ela aparece na última cena deitada em sua cama, embalada pelos ventos do ventilador de Benjamim sob a proteção de São Filomeno, santo protetor dos artistas e palhaços.

$\mathrm{Na}$ figura 3 temos o ventilador e a imagem do santo lado a lado. Tanto o ventilador quanto o santo simbolizam a proteção à manutenção do circo. $O$ santo, elemento simbólico que remete ao componente espiritual, divide espaço com o ventilador no altar improvisado. Assim como as hélices do ventilador, Benjamin está colocado em um mundo "que não para de girar". O ventilador e o santo, Benjamin e o circo, pares que estão colocados nessa intersecção entre o passado e o presente, a tradição e a modernidade. 
Figura 3 - O ventilador de Guilhermina

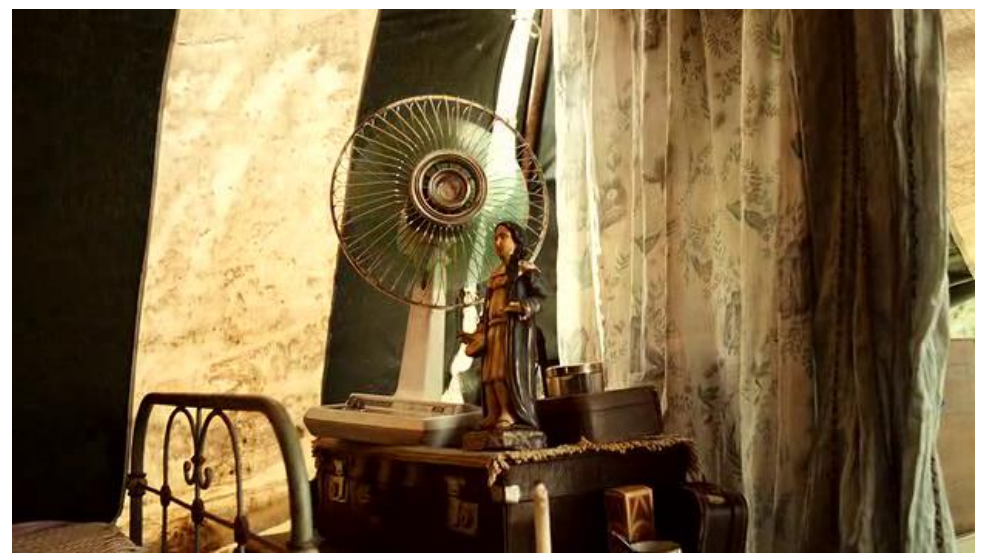

Fonte: https://marmitavirtual.wordpress.com/2012/06/11/quentinhas-visuais-o-palhaco/ . Acessado em 07 de setembro de 2015.

O ventilador, buscado incessantemente por Benjamin, retorna com ele. Ventilando novos ares ao circo, representando a continuidade da atividade tradicional. As coisas voltam a fazer sentido no circo de Benjamin e de seu pai, fazendo jus ao nome Esperança. O papel que o ventilador possui no filme é tão marcante que ele faz parte de uma das identidades visuais e dos cartazes do longa: substituindo o "L" de forma estilizada (Figura 4).

Figura 4 - Cartaz do filme O Palhaço

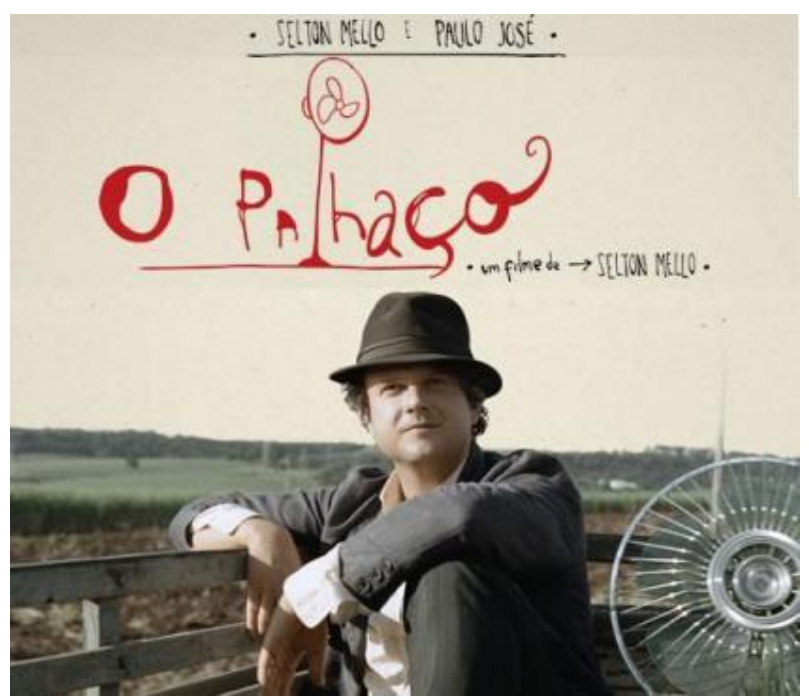

Fonte:http://2001video.empresarial.ws/blog/entrevista-exclusiva-selton-mello-o-palhaco/Acessado em 07 de setembro de 2015. 
Conforme exposto, o ventilador tem no filme uma forte conexão com a identidade de Benjamim. Entretanto, existe outro objeto que também é fortemente relacionado à identidade do personagem: o chapéu. Dentre as diversas tipologias de objetos que nos cercam durante a vida, aqueles que pertencem ao conjunto que denominamos de indumentária são os mais marcantes na construção de uma personalidade, de transmissão de uma mensagem e da nossa própria identidade. Para a criação de personagens, o figurino e todos os seus detalhes são aspectos indispensáveis para dar vida ao personagem, são acessórios e maquiagens que transformam 0 ator em personagem.

Nesse aspecto, podemos perceber a importância do chapéu utilizado por Benjamin e pelo seu palhaço Pangaré. A importância do chapéu na composição do personagem vivido por Selton Mello é reforçada por ele no documentário sobre o filme quando, durante sua entrevista,ele utiliza o chapéu do personagem e fala "[...] aliás, se você estiver se perguntando por que diabos ele está dando essa entrevista de chapéu... eu digo: não é um chapéu qualquer, é o chapéu do Benjamim que eu fiz questão de colocar porque ele me traz recordações, ele tem cheiro de estrada" (MELLO, 2013). A fala do ator sobre o chapéu do figurino de seu personagem é carregada de simbolismos e consegue demonstrar a complexidade e o papel importante que a indumentária tem na criação e no fortalecimento da identidade, inclusive nos personagens.

Nesse mesmo sentido, o livro O casaco de Marx de Peter Stallybras, mostra a importância da roupa para a memória e identidade, "[...] comecei a acreditar que a mágica da roupa está no fato de que ela nos recebe: recebe nosso cheiro, nosso suor, recebe até mesmo nossa forma" (STALLYBRAS, 2000, p.13). Assim, percebemos que a narrativa do ator afirmando que o chapéu tem cheiro de estrada, reforça a teoria de Stallybras, pois nos mostra como a roupa e os objetos têm papel fundamental na memória, mas também têm uma trajetória, o cheiro de viagem está diretamente vinculado à trajetória de vida dos objetos, à sua biografia cultural, conforme propõe Igor Kopytoff (2008).

Erving Goffman (1985) entende que todo aparato da indumentária e demais acessórios utilizados pelos indivíduos fazem parte da "fachada pessoal" que todos criamos para mostrar e criar uma personalidade aos outros. A fachada pessoal representa os elementos utilizados em público, como uma forma de representação constante, mas, ao mesmo tempo, podem caracterizar o verdadeiro eu do indivíduo. Da mesma forma, Michel Maffesoli (1996) associa a indumentária à teatralidade humana, à 
criação de personagens reais que se comunicam através do vestuário. Então, o chapéu de Benjamim torna-se a sua marca registrada, um extended-self como propõe Meneses (1998). Ele é uma continuação do próprio personagem, fazendo com que ele só ganhe vida utilizando-o. São como as marcas pessoais que deixamos nos objetos que utilizamos, eles deixam uma marca em nós e nós neles.

Marcus Dohmann (2013), utilizando o conceito de Enisest Dichter, afirma que "os objetos que nos cercam não têm apenas aspectos utilitários, porém, mais do que isso, atuam como espelhos que refletem as nossas próprias imagens" (Dohmann, 2013: 39). Daí o motivo de Selton Mello utilizar o chapéu durante a entrevista e perceber o aparato simbólico, memorial, identitário que está completamente atrelado a ele, fazendo dele único: "não é qualquer chapéu, é o chapéu do Benjamin". Assim,

[...] o objeto, ou a coisa mesmo, que circula enquanto algo praticado e ritualizado no corpo do social, mediante os atos que o fazem percorrer os complexos (des) caminhos da vida em sociedade, está repleto de sentidos e nexos compartilhados por aqueles que the atribuem valores e simbolismos, sendo que os mesmos emergem da própria experiência intersubjetiva das pessoas em interação entre si, e delas com o mundo. O objeto encerra sempre uma dimensão ético-estética, remetendo ao gesto humano de criar, confeccionar e operar com os mais variados objetos em lugares específicos(SILVEIRA e LIMA, 2005, p.38).

Aos poucos, tais objetos podem adquirir o aspecto de "talismã" (BOSI, 1994), de protetores dos seus proprietários, portá-los é portar a sorte. Por vezes, tornam-se também representativos de alguém, de algo ausente, fortalecem a sua "alma". José Reginaldo Gonçalves (2013) defende que os objetos são portadores de uma alma, de um espírito que conectam e representam pessoas, tempos, momentos vividos. No caso do chapéu, ele é utilizado como uma representação, uma homenagem do ator ao personagem, que ganha vida através do chapéu e de sua narrativa.

Nessa perspectiva, percebe-se a importância que os objetos, tanto o ventilador quanto o chapéu, têm para os aspectos identitários e memoriais dos sujeitos que constituem o filme "O Palhaço". Eles são evocadores de memória, representativos de uma mudança de status, e, ao mesmo tempo, de uma identidade. A ficção, nesse caso, misturada com a realidade do documentário sobre a produção da obra, são fontes para o entendimento dos diversos tipos de suporte de memória que temos ao nosso redor e no aspecto simbólico que ultrapassa as barreiras da materialidade que os objetos nos disponibilizam. 


\section{Considerações Finais}

Os circos e a atividade dos palhaços populares constituem uma tradição que, como tal, é composta de memórias desse saber-fazer rir. Estruturas da comicidade dos clowns, sua inserção no espaço da lona, o poder de ridicularizar a rigidez das estruturas sociais, a itinerância da atividade são alguns elementos que fazem parte dessa atividade e dão sentido a sua existência no corpus das sociedades humanas.

Selton Mello, no roteiro do filme, opta por contrapor os valores tradicionais do trabalho dos circenses, homens e mulheres ambíguos quando vistos em sua inteireza. Admirados no picadeiro e marginalizados fora dele. Artistas que se opõem a uma vida sedentária, mas que são obrigados a adaptar-se às estruturas de uma sociedade com valores calcados no capital e no consumo. Os personagens dependem de renovar figurinos, de consertar o caminhão para seguir viagem, de juntar dinheiro para pagar os empregados, de se submeter às vontades das autoridades locais para seguir com o trabalho. Ambígua também é vida de Benjamin, jovem palhaço que segue a profissão do pai e que herdará o circo. O palhaço que faz rir não sorri. Suas angústias e desejos foram simbolicamente expressos no roteiro pela metáfora do ventilador.

O chapéu para Selton Mello, no documentário sobre a concepção do filme, é a presença do personagem, e o ventilador para Benjamin, no decorrer da obra ficcional, é a busca de si. Chapéu e ventilador são,assim, presença e incompletude, materialização de subjetividades, símbolos afetivos que dão sentido tanto à narrativa da obra quanto à concepção da obra em si. O filme é repleto de pausas, gestos, momentos jocososdramáticos e singelezas interpretativas que dizem desse ambiente repleto de simbologias do circo e também da dureza do cotidiano desses artistas. Antes de ser uma questão do artista circense, o ambiente do filme fala do tempo, de tradição e de transformação, de lembranças e de esquecimentos, desse movimento que é o da própria vida.

\section{Referências}

AUAD, Amanda. O palhaço. Disponível em:<http://www.cinepipocacult.com.br/2011/10/opalhaco.html> Acessado em 13 de setembro de 2015.

BAKHTIN, Mikhail. A cultura popular na Idade Média e no Renascimento: o contexto de François Rabelais. Tradução de Yara Frateschi Vieira. $7^{\mathfrak{a} a}$ ed. São Paulo/Brasília: Hucitec/Editora Universidade de Brasília, 2010.

BOLOGNESI, Mario F. Palhaços. São Paulo: Editora UNESP, 2003. 
BOSI, Ecléa. Memória e sociedade: lembranças dos velhos. São Paulo: Companhia das Letras, 1994.

BURKE, Peter. Cultura popular na Idade Moderna. São Paulo: Cia. Das Letras, 1989.

CERTAU, Michel de. Culturas Populares. In:

A Invenção do Cotidiano.

Petrópolis/RJ: Editora Vozes, 1990. p. 75-90.

DOHMANN, Marcus. A experiência material: a cultura do objeto. Rio de Janeiro: Rio Books, 2013.

FO, Dario. Manual mínimo do ator. Dario Fo; Franca Rame (organização); Trad. Lucas Baldovino, Carlos David Szlack. 3ª Ed. São Paulo: Editora Senac São Paulo, 2004.

GOFFMAN, Erving. A representação do eu na vida cotidiana. Petrópolis: Vozes, 1985.

GONÇALVES, José Reginaldo Santos; BITAR, Nina Pinheiro e GUIMARÃES, Roberta Sampaio [orgs.]. A alma das coisas: patrimônio, materialidade e ressonância. Rio de Janeiro: Mauad X: Faperj, 2013.

HALBWACHS, Maurice (1877-1945). A memória coletiva. São Paulo: Vértice, 1990.

HALL, Stuart. A identidade cultural na pós-modernidade. 11 $\underline{\text { a }}$ Ed. Rio de Janeiro: DPeA, 2011.

KOPYTOFF, Igor. A biografia cultural das coisas: a mercantilização como processo. In: APPADURAI, Arjun. A vida social das coisas: as mercadorias sob uma perspectiva cultural. Niterói: EdUFF, 2008.

MAFFESOLI, Michel. No fundo das aparências. Petrópolis, RJ: Vozes, 1996.

MENESES, Ulpiano. T. B. Memória e cultura material: documentos pessoais no espaço público. In: Revista Estudos Históricos, Rio de Janeiro: Fundação Getúlio Vargas, v.11, n. 21, 1998.

O PALHAÇO. Direção de Selton Mello. Produção: Vania Catani. Roteiro Selton Mello. Interpretes: Selton Mello, Paulo José, Tonico Pereira, TeudaBara, Álamo Facó e outros. [sl.]: Bananeira Filmes, 2011. 90 minutos.

PALHAÇO.DOC.Direção de Marcelo Pontes. Produção: Vania Catani e Selton Mello. [sl.]: Mondo Cane Filmes; Bananeira Filmes, 2011. 46 min. Disponível em: $<$ https://www.youtube.com/watch?v=endEWITZ1j4> Acesso em 27 de abril de 2015.

SILVA, Erminia. Circo-teatro: Benjamin de Oliveira e a teatralidade circense no Brasil. São Paulo: Altana, 2007.

O Circo sempre esteve na moda: A contemporaneidade da teatralidade circense. Revista Palco Aberto: malabares, circo e arte de rua. Ano 4. São Paulo, novembro de 2008. 
SILVEIRA, Flavio Leonel A. e LIMA FILHO, Manuel Ferreira. Por uma antropologia do objeto documental: entre a "alma das coisas" e a coisificação do objeto. Horizontes Antropológicos. Porto Alegre, ano 11, n. 23, p. 37-50, jan/jun 2005.

SOUSA JUNIOR, Walter de. Mixórdia no picadeiro: circo, circo-teatro e circularidade cultural na São Paulo das décadas de 1930 a 1970. São Paulo: USP, 2008. 204f. Tese de Doutorado. Escola de Comunicações e Artes. Teoria e Pesquisa em Comunicação.

STALLYPRASS, Peter. O casaco de Marx: roupas, memória, dor. Belo Horizonte: Autêntica, 2000. 